\title{
Epidemiology of cutaneous leishmaniasis in the endemic area of Jericho, Palestine
}

A. Al-Jawabreh, ${ }^{1}$ F. Barghuthy, ${ }^{2}$ L.F. Schnur, ${ }^{3}$ R.L. Jacobson, ${ }^{3}$ G. Schönian ${ }^{4}$ and Z. Abdeen $^{2}$

$$
\begin{aligned}
& \text { وبائيات داء الليشمانيات الجلدي في منطقة موطونة بها في في أريحا، فلسطين }
\end{aligned}
$$

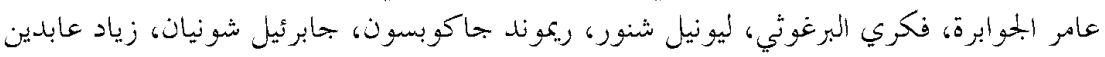

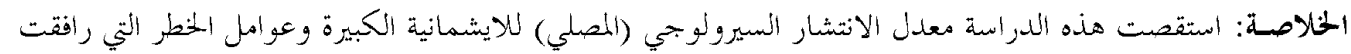

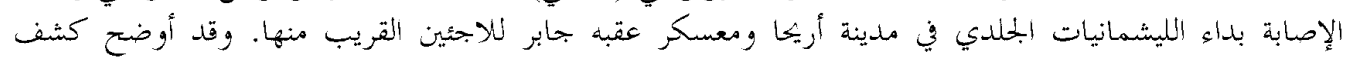

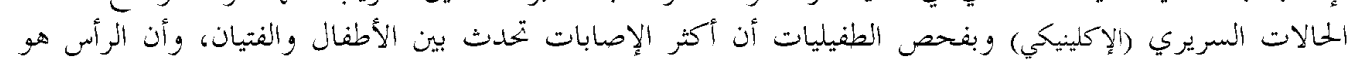

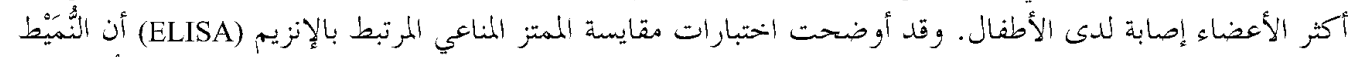

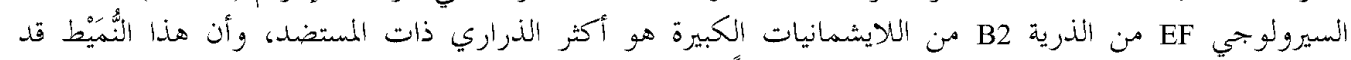

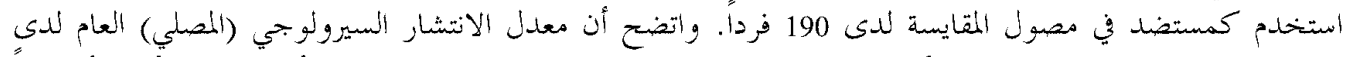

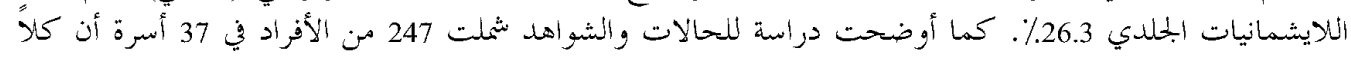

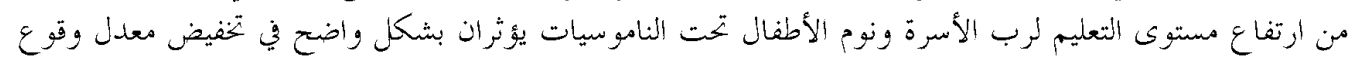

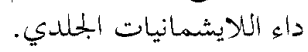

ABSTRACT This study of cutaneous leishmaniasis in Jericho city and the adjacent Aqbat-Jaber refugee camp investigated the seroprevalance of Leishmania major and the risk factors associated with acquiring the disease. Clinical and parasitology identification of cases showed children and young men were more affected, with the head most affected in children. Enzyme-linked immunosorbent assay (ELISA) was used to test sera from 190 individuals. The overall seroprevalence of cutaneous leishmaniasis was $26.3 \%$. A casecontrol study of 247 individual in 37 households showed that a higher level of education of the head of the household and having children sleep under bed nets were significantly related to a lower incidence of cutaneous leishmaniasis.

Epidémiologie de la leishmaniose cutanée dans la zone endémique de Jéricho (Palestine) RESUME Cette étude sur la leishmaniose cutanée dans la ville de Jéricho et le camp de réfugiés adjacent Aqbat-Jaber a porté sur la séroprévalence de Leishmania major et les facteurs de risque associés à l'acquisition de la maladie. L'identification clinique et parasitologique des cas a montré que les enfants et les hommes jeunes étaient davantage touchés, la tête étant la plus affectée chez les enfants. La techique de dosage immuno-enzymatique (ELISA) a été utilisée pour tester les sérums de 190 individus. La séroprévalence globale de la leishmaniose cutanée était de 26,3\%. Une étude cas-témoins menée chez 247 individus dans 37 foyers a révélé qu'un niveau d'instruction plus élevé du chef de famille ainsi que le fait que les enfants dorment sous des moustiquaires étaient liés de façon significative à une plus faible incidence de la leishmaniose cutanée.

${ }^{1}$ Islah Medical Laboratory, Islah Charitable Social Society, Jericho, Palestine.

${ }^{2} \mathrm{Health}$ Research Centre, Faculty of Medicine, Al-Quds University, East Jerusalem, Palestine.

${ }^{3}$ Hadassah Medical School, Hebrew University, Jerusalem, Israel.

${ }^{4}$ Institute of Microbiology and Hygiene, Humboldt University, Charité, Berlin, Germany.

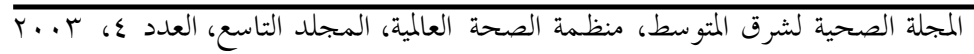




\section{Introduction}

Jericho District, situated on the Palestinian side of the Jordan Valley, is the centre of a region where simple cutaneous leishmaniasis (CL) caused by Leishmania major is hyperendemic [1,2,]. It is a vector-borne, zoonotic disease. Female sand flies of the species Phlebotomus papatasi are the vectors and fat sand rats of the species Psammomys obesus are the natural animal reservoir hosts [3-5]. The sand flies and rodents live in very close association within the rodent burrows. This maintains high rates of infection in the vectors and ensures effective transmission of the parasite among the rodent hosts [3]. Female $P h$. papatasi are zoophilic, transmitting the parasite efficiently from rodent to rodent, and anthropophilic, transmitting them efficiently from the rodents to humans [6]. It is the abundance of vectors living in very close association with highly susceptible rodent hosts and the equal readiness of the vectors to feed on humans that accounts for the hyperendemicity of CL among humans in the Jordan Valley [3].

From the time of the first parasitologically confirmed cases in the Jordan Valley $[3,7,8]$, CL caused by L. major has become an ever-increasing public health problem. The only epidemiological study carried out on the city's human population was done on schoolchildren and showed the prevalence of CL among them was 84\% using the leishmanin skin test [2]. Following the withdrawal of the Israeli administration in 1994 and the establishment of the Palestinian Authority, the region has undergone many economic and demographic changes. The study reported here was a case-control household study that aimed to identify the risk factors associated with CL in the vicinity of Jericho following these changes. An enzyme-linked immunosrbent assay
(ELISA) seroprevalence survey was undertaken alongside.

\section{Background: epidemiology of CL in the area}

The Dead Sea lies at the lowest point on earth and is surrounded by rocky mountainous desert and fed by the River Jordan at its northern end. Jericho, the centre of the study area, is between $260-400 \mathrm{~m}$ below sea level. Wadi Qelt brings an abundance of spring water and additional rainwater during the winter, which makes the area green and lush all year round.

According to the Palestinian National Census of 1997, the population of Jericho city was 14647 and that of the Aqbat-Jaber refugee camp was 4581 . Today's Jericho, despite being an ancient city, has more in common with a large rural village than a well-established city.

From a database of cases identified between 1994-99, geographic and seasonal patterns of CL have been plotted for the area. One-third of all of 152 confirmed cases of CL were diagnosed in 1995, constituting a peak that coincided with the highest annual rainfall during the period. The increased number of cases of CL in 1995 also followed the withdrawal of Israeli forces from the Jericho region in 1994 as immunologically naive populations from other Palestinian areas came into this area of high endemicity. However, in general, a decreasing trend in the number of positive cases in Jericho district during 1994-99 was demonstrated.

More than half of CL cases were diagnosed between October and January, indicating a seasonal pattern that more or less correlated with the local sand fly season, though some cases persisted through the whole year.

Most of the cases of CL were clustered on the periphery of Jericho city and Aqbat-

المجلة الصحية لشرق المتوسط، منظمة الصحة العالمية، المجلد التاسع، العدد ؟، ب..ب 
Jaber refugee camp and nearly half of the cases $(45 \%)$ in Jericho city were in the south-eastern sections of the city periphery close to farmland on both sides of Wadi Qelt that runs through Jericho city. This provides a suitable environment for the colonies of sand rats and sand flies. The distribution of cases in Aqbat-Jaber camp were similar to that of the city.

\section{Methods}

\section{Passive surveillance of $C L$ in Jericho district}

From 1994-99, data was collected about patients with suspected CL lesions referred for diagnosis to the Islah Medical Laboratory in Jericho District. Diagnosis of CL was based on the presence of typical skin lesions and a positive parasitology test.

Two methods were routinely used for parasitological identification of CL. From 1994-98, stained smears were used. Between 4 to 8 smears were prepared from the cutaneous lesions of each patient. These were stained with Giemsa and examined microscopically for amastigotes. From 1998, tissue cultures were used for the growth of promastigotes also. Tissue aspirates from lesions were cultured in rabbit blood-agar medium, containing $10 \%$ defibrinated blood and antibiotics (penicillin at $200 \mathrm{IU} / \mathrm{mL}$ and streptomycin at $200 \mu \mathrm{g} /$ $\mathrm{mL}$ ). Two tubes of medium were inoculated for each individual. The cultures were incubated at $22-28{ }^{\circ} \mathrm{C}$ and examined for promastigotes after 1 week then every 3 days for 4 weeks before being considered negative.

\section{Case-control household study}

An unmatched case-control approach was used to select 247 participants for the risk assessment household survey conducted in August 1999. The case group was pur- posefully selected from those cases of CL living in Jericho city and Aqbat-Jaber camp. The control group was randomly selected from the same areas. A total of 139 cases from 19 households and 108 controls from 18 households were selected. Field workers were provided with maps showing the locations of the households. Of the 37 households, 22 were in Jericho city and 15 in the adjacent refugee camp.

Interviews were conducted on the weekend (Fridays) to ensure participation of most household heads and members. When the head of household or most of members were not available at the time of the interview, a date was set for another visit. This time, the interview took place with the head of the household in both groups in the 37 households regardless of the number of household members attending. Two health personnel were present at interviews and, after each interview, the questionnaire was passed to the other interviewer to be checked for missing data.

A questionnaire was used that collected information about the vector and human hosts $[3,49,10]$. Questions covered the demographic characteristics of the subjects (age, sex, ethnicity, education, occupation), features of the house (presence of pets, springs, trees, sand rat burrows, type of roofing) and behaviour of household members (where they sleep, use of bed nets, etc.).

\section{Seroprevalence survey on CL cases and uninfected household members}

The seroprevalence survey was carried out on previously referred CL cases during 1994-99 and their neighbouring uninfected household members. Serum samples were collected from 190 of the 247 individuals participating in the risk assessment household survey.

المجلة الصحية لشرق المتوسط، منظمة الصحة العالمية، المجلد التاسع، العدد ع، ب...T 
An extra 11 serum samples from parasitologically confirmed cases were added to establish the validity of the ELISA system. Ten of these sera were from local cases referred to the Islah Medical Centre in Jericho and 1 was from a subject immunized by an artificially induced infection (leishmanization) 32 years previously, with a local strain from the vicinity of Jericho, $L$. major (MHOM/IL/67/Jericho II LRCL137). Another 10 sera collected from residents not from the Jericho district were also included for validation. The sera were labelled and stored at $-20^{\circ} \mathrm{C}$ until tested.

Species and strains of Leishmania differ antigenically [13]. The antigenicity of 3 different strains was tested to select the most suitable strain for use in the ELISA. These were L. major (MHOM/PS/98/Islah 402 LRC-L752) excreted factor (EF) subserotype A1 strain, L. major (MTAT/KE/??/ NLB-089 LRC-L456) EF subserotype $B_{2}$ strain and $L$. donovani infantum (MCAN/ IL/96/ LRC-L693) excreeted factor (EF) subserotype $B_{2}$ strain. The most antigenic strain among those investigated was the one giving the highest optical density reading for the same protein content when tested against selected clinical samples. The strains were grown as promastigotes in Schneider's Drosophila medium (Gibco). The promastigotes were harvested at log phase by centrifugation at $4000 \mathrm{~g}$ for 10 min at $4{ }^{\circ} \mathrm{C}$. The pellet was washed twice in phosphate-buffered saline (PBS) and suspended in sterile PBS. The cells were lysed by repeated freezing in liquid nitrogen and thawing in a water-bath at $37^{\circ} \mathrm{C}$. The protein concentrations of the lysates were determined by the Bradford assay [11]. The ELISA was done as described by Jaffe and McMahon-Pratt [12]. Three sets of microtitre plates were coated with the antigens of 3 different strains mentioned above. They were assayed against 4 sera: 2 test sera from parasitologically confirmed human cases of CL caused by L. major from the Jordan Valley, 1 positive control serum from a dog with VL caused by $L$. donovani infantum from Israel and 1 negative control human serum (Sigma, Israel). These sera were tested at dilutions between 1:2 and 1:2000 to select the most antigenic strain and determine the cut-off value and its corresponding dilution. The cut-off value was calculated as the value given by the negative control plus 3 standard deviations.

\section{Analysis}

Fisher's exact test was applied to determine statistical differences between the case and control groups.

\section{Results}

\section{Passive surveillance of $\mathrm{CL}$}

Of the 152 individuals confirmed parasitologically with CL during 1994-99, 92 (60.5\%) were children, 60 (39.5\%) were adults. The largest group of children infected with CL were aged 0 to 4 years (58/92). Of the infected adults, the largest group were 20 to 29 years old (27/60). More than half of the infected children (53/92) and two-thirds of the infected adults (39/60) were male.

Table 1 shows that, in children, the head was more frequently (61.3\%) the site of lesions than other body sites, whereas the limbs were more involved in adults (78.3\%). This showed a significant association between age and site of lesion $(P<$ 0.001 ). The distribution of lesions in the head area had a certain pattern with lesions more often appearing on the cheek (29.6\% of 115 lesions), than on the nose (23.5\%), the forehead $(14.8 \%)$ or the chin $(13.0 \%)$.

\section{Seroprevalence survey}

The most antigenically suitable strain was the Kenyan subserotype $\mathrm{B}_{2}$ strain L. major

المجلة الصحية لشرق المتوسط، منظمة الصحة العالمية، المجلد التاسع، العدد ؟، ب..ب 
Table 1 Distribution of cutaneous leishmaniasis lesions by site of lesion and age group

\begin{tabular}{|c|c|c|c|c|c|c|c|c|}
\hline & \multicolumn{2}{|c|}{ Head and neck } & \multicolumn{2}{|c|}{ Upper limbs } & \multicolumn{2}{|c|}{ Lower limbs } & \multicolumn{2}{|c|}{ Total } \\
\hline & No. & $\%$ & No. & $\%$ & No. & $\%$ & No. & $\%$ \\
\hline Children & 95 & 61.3 & 36 & 23.2 & 24 & 15.5 & 155 & 100.0 \\
\hline Adults & 20 & 21.7 & 38 & 41.3 & 34 & 37.0 & 92 & 100.0 \\
\hline Total & 115 & 46.6 & 74 & 30.0 & 58 & 23.5 & $247^{a}$ & 100.0 \\
\hline
\end{tabular}

and it was used in the subsequent serological studies. The local Palestinian subserotype A strain of $L$. major and the Israeli strain of $L$. infantum were found to be less antigenic. The cut-off value of ELISA was 0.245 with the subserotype $B_{2}$ strain of $L$. major, which coincided with a serum dilution of 1:200.

Fifty of the serum samples collected from the 190 individuals from the Jericho city and Aqbat-Jaber refugee camp were ELISA positive, indicating a seroprevalence of $26.3 \%$ among cases diagnosed during 1994-99 and their neighbouring uninfected household members. The 190 individuals fell into 3 groups: 24 (12.6\%) were positive by smear; 14 (7.4\%) were considered to have been exposed because they either had lesions during the study period or claimed to have had CL in the past; 152 (80.0\%) were healthy uninfected individuals. Sixteen of the 24 cases (66.7\%) with positive smears were ELISA-positive. In the exposed group, 6 out of 14 cases (42.9\%) were ELISA-positive. In the healthy uninfected group, 25 of the 152 subjects (16.5\%) who had no history of CL were ELISA-positive (Figure 1).

Of these 190 samples, 109 were used to evaluate the diagnostic performance of ELISA using direct smear test as the gold standard diagnostic test. The ELISA system employed in this study had a relatively good sensitivity of $67 \%(16 / 24)$ with a positive predictive value of 55\% (16/29) and a high specificity of $85 \%$ (72/85) with a negative predictive value of $90 \%$ (72/80) (Table 2).

\section{Case-control household study}

Tables 3 and 4 show the analysis of the sociodemographic, environmental and behavioural determinants of CL in 37 households. The level of education of head of the household was significantly $(P<0.05)$ related to the incidence of CL in a household; when the head of the household had less than 10 years education, it was more likely that a household member would acquire CL. In addition, ethnic groups other than native or Bedouin were at 3-fold increased risk of contracting the disease compared with the native group, and this was statistically significant $(P<0.05)$. Also, children's sleeping under bednets was shown to significantly reduce the probability of acquiring $C L$ for children $(P<0.05)$.

There was a higher risk of contracting infection among males; in household members living close to farms; in families with pets; in houses with asbestos/straw roofs; in houses having non-citrus trees in their

المجلة الصحية لشرق المتوسط، منظمة الصحة العالمية، المجلد التاسع، العدد ؟، ب.. 


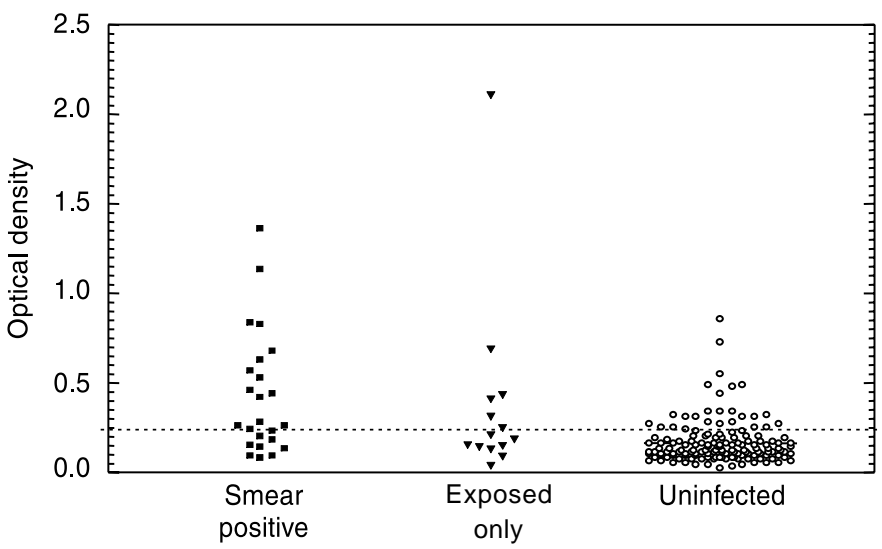

Figure 1 ELISA results of the serosurvey ( $n=190$ individuals)

gardens; and among individuals sleeping in house yards or those leaving air-conditioning on when sleeping. However, these did not reach statistical significance. On the other hand, there was a non-significant reduced risk among those having springs close to their houses; having screened windows; or using the water type of air-conditioning.

\section{Discussion}

The results of the ELISA serological survey from the household sample showed a seroprevalence of CL of 26.3\% (50/190). This contrasts but does not conflict with the earlier study done by Alvarado et al., who reported a higher prevalence of 56\% (14/ 21) among schoolchildren from Jericho on

Table 2 Enzyme-linked immunosorbant assay (ELISA) results for parasitologically confirmed cases of cutaneous leishmaniasis $(\mathrm{CL})$ and for healthy uninfected individuals

\begin{tabular}{lccccrc}
\hline CL status & \multicolumn{2}{c}{ ELISA positive } & \multicolumn{2}{c}{ ELISA negative } & \multicolumn{2}{c}{ Total } \\
& No. & $\%$ & No. & $\%$ & No. & $\%$ \\
\hline CL positive $^{\mathrm{a}}$ & 16 & 66.7 & 8 & 33.3 & 24 & 100.0 \\
CL negative $^{\mathrm{b}}$ & 13 & 15.3 & 72 & 84.7 & 85 & 100.0 \\
Total & 29 & 26.6 & 80 & 73.4 & 109 & 100.0 \\
\hline
\end{tabular}

${ }^{a}$ Confirmed by direct smear.

${ }^{b}$ Healthy group. 


\begin{tabular}{|c|c|c|c|c|}
\hline Variables & $\begin{array}{c}\text { Cases } \\
(n=140) \\
\%\end{array}$ & $\begin{array}{c}\text { Controls } \\
(n=107) \\
\%\end{array}$ & $\begin{array}{l}\text { Odds } \\
\text { ratio }\end{array}$ & $95 \% \mathrm{Cl}$ \\
\hline \multicolumn{5}{|l|}{ Age (years) } \\
\hline $20-29^{a}$ & 11.1 & 6.3 & 1 & \\
\hline 30-39 & 66.7 & 56.3 & 0.67 & $0.02-12.2$ \\
\hline $40+$ & 22.2 & 37.5 & 0.33 & $0.01-8.01$ \\
\hline \multicolumn{5}{|l|}{ Sex } \\
\hline Female $^{a}$ & 5.3 & 5.6 & 1 & \\
\hline Male & 94.7 & 94.5 & 1.06 & $0.0-42.8$ \\
\hline \multicolumn{5}{|l|}{ Ethnicity of $\mathrm{HOH}$} \\
\hline Locally borna & 5.3 & 22.2 & 1 & \\
\hline Bedouin & 26.3 & 0 & - & \\
\hline Other & 68.4 & 77.8 & 3.71 & $1.52-10.71$ \\
\hline \multicolumn{5}{|l|}{ Ethnicity of spouse } \\
\hline Locally born ${ }^{a}$ & 0 & 17.7 & NV & NV \\
\hline Bedouin & 26.3 & 0 & & \\
\hline Other & 73.7 & 82.4 & & \\
\hline \multicolumn{5}{|c|}{ Education of $\mathrm{HOH}$ (years) } \\
\hline $0-10^{a}$ & 84.2 & 47.1 & 1 & \\
\hline$>10$ & 15.8 & 53.0 & 0.17 & $0.03-0.97^{*}$ \\
\hline \multicolumn{5}{|c|}{ Education of spouse (years) } \\
\hline $0-10^{\mathrm{a}}$ & 79.0 & 70.6 & 1 & \\
\hline$>10$ & 21.1 & 29.4 & 0.64 & $0.11-3.67$ \\
\hline \multicolumn{5}{|l|}{ Occupation of $\mathrm{HOH}$} \\
\hline Soldier & 22.2 & 0 & NV & NV \\
\hline Trader & 11.1 & 22.2 & & \\
\hline Manual worker ${ }^{b}$ & 33.3 & 22.2 & & \\
\hline Technical & 11.1 & 8.0 & & \\
\hline Driver & 0 & 5.6 & & \\
\hline Farmer & 16.7 & 5.6 & & \\
\hline \multicolumn{5}{|c|}{ Occupation of spouse } \\
\hline Housewife & 100 & 64.3 & NV & NV \\
\hline Other & 0 & 35.7 & & \\
\hline
\end{tabular}

$\mathrm{HOH}=$ head of household.

$N V=$ not valid

${ }^{*} \mathrm{P}<0.05$.

${ }^{a}$ Reference category.

${ }^{b}$ Skilled or unskilled.

applying a lymphocyte proliferation assay (LPA) and a much higher prevalence of $84 \%$ (21/25) among the same children on applying leishmanin skin tests [2]. The LPA and leishmanin skin tests measure the host's cellular immune response that devel-

المجلة الصحية لشرق المتوسط، منظمة الصحة العالمية، المجلد التاسع، العدد ع، ب... 


\begin{tabular}{|c|c|c|c|c|}
\hline Variables & $\begin{array}{c}\text { Cases } \\
(n=140) \\
\%\end{array}$ & $\begin{array}{c}\text { Controls } \\
(n=107) \\
\%\end{array}$ & $\begin{array}{l}\text { Odds } \\
\text { ratio }\end{array}$ & $95 \% \mathrm{Cl}$ \\
\hline \multicolumn{5}{|l|}{ Features of the area } \\
\hline Presence of farm within $200 \mathrm{~m}^{\mathrm{a}}$ & 66.7 & 50.0 & 2.00 & $0.43-9.64$ \\
\hline Presence of spring in the area & 11.1 & 22.2 & 0.44 & $0.05-3.50$ \\
\hline $\begin{array}{l}\text { Having seen sand flies in the } \\
\text { area }\end{array}$ & 5.6 & 5.6 & 1 & NV \\
\hline $\begin{array}{l}\text { Presence of animal burrows } \\
\text { around the house } \\
\text { Type of trees in the garden }\end{array}$ & 5.6 & 5.6 & 1 & NV \\
\hline Citrus & 45.5 & 85.7 & 7.20 & $0.80-79.38$ \\
\hline Others & 54.6 & 14.3 & & \\
\hline \multicolumn{5}{|l|}{ Features of the house } \\
\hline Cement & 83.3 & 88.9 & 1 & $0.18-16.33$ \\
\hline Others (asbestos/straw) & 16.7 & 11.1 & 1.60 & \\
\hline $\begin{array}{l}\text { Presence of air-conditioning } \\
\text { Type of air-conditioning }\end{array}$ & 88.9 & 88.9 & 1 & NV \\
\hline Fan & 37.5 & 27.8 & 0.64 & $0.12-3.39$ \\
\hline Water & 62.5 & 72.2 & & \\
\hline Screens on windows ${ }^{a}$ & 38.9 & 72.2 & 0.69 & $0.17-2.71$ \\
\hline \multicolumn{5}{|l|}{ Family habits } \\
\hline $\begin{array}{l}\text { Presence of pets } \\
\text { Having evening tea in house }\end{array}$ & 44.5 & 33.3 & 1.60 & $0.34-7.70$ \\
\hline $\operatorname{yard}^{\mathrm{a}}$ & 94.1 & 94.1 & 1 & NV \\
\hline $\begin{array}{l}\text { Sleeping in house yard } \\
\text { Leaving air-conditioning during }\end{array}$ & 50.0 & 27.8 & 2.60 & $0.53-13.22$ \\
\hline sleeping ${ }^{a}$ & 72.2 & 66.7 & 1.30 & $0.25-6.78$ \\
\hline Children sleeping in bednets ${ }^{a}$ & 5.6 & 38.9 & 0.09 & $0.00-0.96^{*}$ \\
\hline
\end{tabular}

$\star P<0.05$

$N V=$ not valid

${ }^{a}$ Reference category, i.e. the absence of the potential determinant of infection.

ops after a period of active infection and is part of the mechanism leading to self-cure and life-long protection against re-infection. Therefore, all, or very nearly all, cases of CL caused by L. major would be expected to acquire a measurable cellular response.

In contrast, the serum antibody levels measured by ELISA are the product of a humoral immune response. This commonly occurs in cases of visceral leishmaniasis (VL) caused by L. donovani donovani and L. $d$. infantum and is used in the diagnosis of VL. On treating and curing such cases, their antibody levels disappear. Finding measurable levels of anti-leishmanial antibodies in the sera of $43 \%$ of previously exposed subjects and $16 \%$ of subjects with 
no signs of CL is an interesting but inexplicable novel finding, as only active cases would be expected to produce measurable antibody levels. Thus, antibody levels are not as useful in the diagnosis of CL caused by $L$. major and L. tropica as leishmanin skin testing and classical parasitological diagnosis. Alvarado et al. have adequately demonstrated this [2].

One-third (8/24) of the parasitologyconfirmed cases were ELISA-negative. The reason for this is difficult to gauge. As the immune response to CL caused by $L$. major and L. tropica is largely cellular, the presence and role of the antibodies, when they occur, has not been well studied. In the present case, we might speculate that since the time of becoming infected was not known, antibody levels had not yet risen sufficiently or they had already declined. Klaus et al. demonstrated that antibody levels remain constant for 28 weeks after infection before they decline [14]. The time between the occurrence of lesions and the serosurvey was only 1 to 3 weeks in some of our seronegative cases. Also, in our study, one case who was initially seronegative became seropositive 6 months later. The seropositive subjects in the uninfected group can be explained in two possible ways. Some might have been exposed to CL but denied it or had forgotten. Others might have been genuine false positives owing to cross-reactivity with other infections $[15,16]$.

The risk assessment survey showed that only the factors significantly related to a lower incidence of cutaneous leishmaniasis were a higher level of education of the head of the household and having children sleep under bednets. Thus, low educational status can be considered a risk factor for acquiring CL. It is likely that the head of household influences the personal hygiene of family members and cleanliness of the dwelling place and makes economic decisions such as buying air conditioners and window nets. Heads of households will also direct the seasonal movement of family and related behaviour, such as where the family lives (living close to the city boundaries, which are higher prevalence areas, or on farmlands), sleeping patterns (in- or out-of-doors) and use of bednets. Educated people tend to be more aware of health issues and activities, and are more cooperative with local health authorities about the control measures against leishmaniasis.

The parasitology results showed a high rate of infection in children. In a hyperendemic situation, we could expect that children will acquire CL easily and that this gives them a protective immunity as adults. The clinical findings were that children had more lesions on the face and head. This is probably owing to children being fully covered during the night with only their heads exposed from their bedclothes. Head lesions were mainly on the cheek and the nose possibly owing to protrusion of the face topography. Also, the softness of the skin of the face makes it a preferable site for feeding from. Babies are easy targets and prey to multiple bites whether they sleep outdoors or indoors, particularly in the long hot summer period. The clinical pattern of CL corroborates the risk assessment findings that children sleeping under bed nets are at lower risk of acquiring CL, presumably as they are less exposed to the sand fly vector during its active hours.

In adults, the limbs were more involved. Males in the 20-29 year age range are at especially high risk because of their more extensive activity and mobility in the foci of CL during the evening hours. Many of the adult males were Palestinian soldiers who became infected during their military service. This was also experienced by the Israeli army when it occupied these high

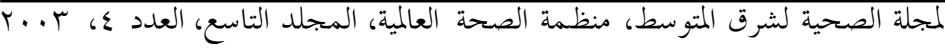


prevalence areas after the 1967 war [17]. Males seemed to be at a higher risk than females of acquiring CL. The low incidence of CL among females might have a cultural and social background. Local women tend to cover their heads and limbs and are obliged to be home before evening, the onset of the period of sand fly activity. This reduces both the duration and extent of bodily exposure to infection.

\section{Acknowledgements}

This investigation received technical and financial support from the joint WHO Eastern Mediterranean Region (EMRO), Division of Communicable Diseases
(DCD) and the WHO Special Programme for Research and Training in Tropical Diseases (TDR): the EMRO/DCD/TDR Small Grants Scheme for Operational Research in Tropical and Communicable Diseases. Deutsche Forschungsgemeinschaft (DFG) also contributed to the study.

The epidemiological and diagnostic part of the study was carried out at Islah Charitable Social Society's medical centre in Jericho with significant help from Mrs Hanan Al-Jawabreh, in collaboration with the Health Research Centre at Al-Quds University. The serological part was done at the Hebrew University-Hadassah Medical School, Jerusalem.

\section{References}

1. Arda HM. A report on cutaneous leishmaniasis in the West Bank of Jordan. Jordan medical journal, 1983, 17(1):5763.

2. Alvarado $\mathrm{R}$ et al. Delayed-type hypersensitivity and lymphocyte proliferation in response to Leishmania major infection in a group of children in Jericho. Transactions of the Royal Society of Tropical Medicine and Hygiene, 1989, 83:189-92.

3. Schlein $Y$ et al. Leishmaniasis in the Jordan Valley II. Sandflies and transmission in the central endemic area. Transactions of the Royal Society of Tropical Medicine and Hygiene, 1982b, 76:5826.

4. Schlein $Y$ et al. Leishmaniasis in Israel: reservoir hosts, sandfly vectors and leishmanial strains in the Negev, Central Arava and along the Dead Sea. Transactions of the Royal Society of Tropical Medicine and Hygiene, 1984, 78:480-4.
5. Gunders AE et al. Isolation of Leishmania species from Psammomys obesus in Judea. Transactions of the Royal Society of Tropical Medicine and Hygiene, 1968, 62:465.

6. Ashford RW. Leishmaniasis reservoirs and their significance in control. Clinics in dermatology, 1996, 14:523-32.

7. Janini $\mathrm{R}$ et al. Incrimination of Phlebotomus papatasi as vector of Leishmania major in the southern Jordan Valley. Medical and veterinary entomology, 1995, 9(4):420-2.

8. deBeurman. Leishmaniosis ulcerosa cutis un cas de bouton des pays chauds contracté à Jericho. Revue de médecine et d'hygiène tropicales, 1910, 7:265-7.

9. Mbarki $L$ et al. Monitoring cutaneous leishmaniasis with GIS. In: DeSavigny D, Wijeyaratne P, eds. GIS for health and the environment. Ottawa, Canada, Inter- 
national Development Research Centre, 1996.

10. Killick-Kendrick R. The biology and control of phlebotomine sandflies. Clinics in dermatology, 1999, 17:279-89.

11. Bradford MM. Rapid and sensitive method for the quantitation of microgram quantities of protein utilizing the principle of protein-dye binding. A rapid and sensitive method for the quantitation of protein utilizing the principle of proteindye binding. Analytical biochemistry, 1976, 72:248-54.

12. Jaffe CL, McMahon-Pratt D. Serodiagnostic assay for visceral leishmaniasis employing monoclonal antibodies. Transactions of the Royal Society of Tropical Medicine and Hygiene, 1987, 81:587-94.

13. Schnur LF, Sarfstein R, Jaffe CL. Monoclonal antibodies against leishmanial membranes react with specific excreted factors (EF). Annals of tropical medicine and parasitology, 1990, 84:447-56.

14. Klaus SN et al. Serial study of the immune response of an individual with exacerbated simple cutaneous leishmaniasis. Israel journal of medical sciences, 1994, 30:19-21.

15. Kar K. Serodiagnosis of leishmaniasis. Critical reviews in microbiology, 1995, 21(2):123-52.
16. Mosleh IM et al. Serodiagnosis of cutaneous leishmaniasis in Jordan using indirect fluorescent antibody test and the enzyme-linked immunosorbent assay. Acta tropica, 1995, 59(2):163-72.

17. Naggan L et al. Ecology and attempted control of cutaneous leishmaniasis around Jericho, in the Jordan Valley. Journal of infectious diseases, 1970, 121:427-32.

18. Neouimine NI. Leishmaniasis in the Eastern Mediterranean Region. Eastern Mediterranean health journal, 1996, 2:94-101.

19. Palestinian annual communicable disease report, 1999. Ramallah, Palestinian Authority Ministry of Health, 1999.

20. Morsy AT. Cutaneous leishmaniasis in Egypt (review and comment). Journal of the Egyptian Society of Parasitology, 1996, 26:105-30.

21. El-Safi SH, Peters W. Studies on the leishmaniases in the Sudan. 1. Epidemic of cutaneous leishmaniasis in Khartoum. Transactions of the Royal Society of Tropical Medicine and Hygiene, 1991, 85:44-7.

المجلة الصحية لشرق المتوسط، منظمة الصحة العالمية، المجلد التاسع، العدد ع، ب... 